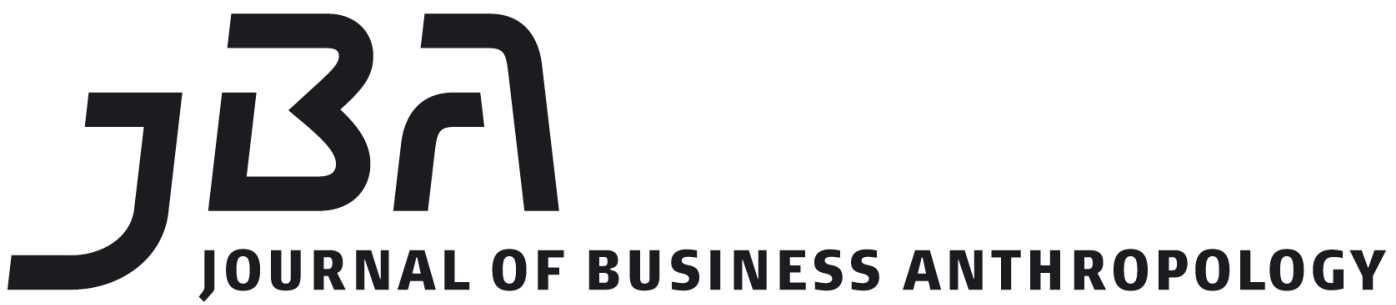

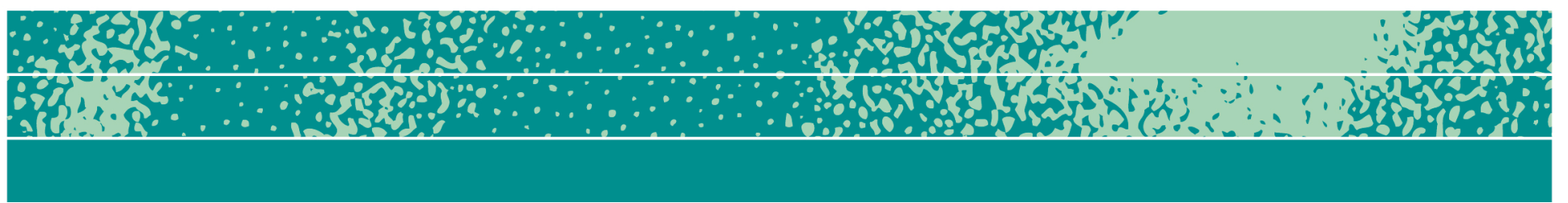

\section{The Job is in the Field: Notes from Municipal Anthropology}

\author{
Robin Nagle
}

\begin{abstract}
The Department of Sanitation in New York City is a mayoral agency with a key role in municipal government, but it also has the attributes of a powerful corporation. With an annual budget in excess of a billion dollars, it hires, monitors, and replaces private vendors and contractors for a host of essential services, balances the often conflicting demands of several unions, and answers to a watchful but perpetually critical public. As the Department's anthropologist-in-residence since 2006, my work has included consulting, advocacy, collaboration, education, and organizing various projects focused on the interface between Sanitation and that larger public. These efforts have helped me understand the urban environment from the perspective of those who keep it clean, while also letting me become intimately acquainted with the complex dynamics of a workforce that is generally scorned even while it is fundamental to the well-being of the metropolis it serves. This paper considers the model of anthropologist-in-residence as I've structured it within the DSNY, discusses contributions to an anthropology of organizations, and explores the possibility of similar relationships between anthropologists and other public and private institutions.
\end{abstract}

Page 1 of 17

JBA 6(1): 41-57 Spring 2017

(C) The Author(s) 2017 ISSN 2245-4217

www.cbs.dk/jba 


\section{Keywords}

Bureaucracy, organizations, solid waste management, public institutions, urban studies

\section{Of/for/with}

Since 2006, I have been the anthropologist-in-residence for New York City's Department of Sanitation (DSNY). The Department is a municipal government agency, not a private business or corporation, and no one within it ever requested my help as a consultant or as an advisor; rather, I asked to learn about it and then to become part of its structure. I created the title "anthropologist-in-residence" to anchor my place in Sanitation after I'd been doing ethnographic research with the Department for four years. As far as I know, it's a unique position in anthropology and in government.

Though I invented the role, wrote a proposal to explain it, advocated for it, and was delighted when it was adopted, I was slow to understand its full range of privileges and limitations. The status "in residence" has much potential for anthropology, to the mutual benefit of the discipline and the host organization, but it creates an essential responsibility and a perpetual challenge: I am always striving to balance an anthropology of the DSNY with an anthropology for it. Those aims are sometimes contradictory. As I'll show in this essay, the conflict is resolved by forging a continually collaborative anthropology with the organization.

\section{Just say no}

Until recently, garbage was considered a curious focus for social science. The assumption even among anthropologists was that, if it belonged in the discipline at all, it was the purview of archaeology (see Martin and Russell 2000; Cantwell and Wall 2003: 227-241; Rathje 1984; Rathje and Murphy 1992). Investigating it from a socio-cultural perspective seemed to have occurred to few scholars. ${ }^{1}$ When I talked to professional solid waste managers, they were puzzled that an academic not trained in civil or chemical engineering, urban planning, materials science, or environmental economics would want to learn about trash systems. They were especially perplexed that I wanted to study the cultural underpinnings and social patterns of municipal sanitation work.

But I knew that New York's Sanitation Department had rich ethnographic potential. A quasi-military urban subculture, its approximately 9,000 members serve 8.4 million people through a tightly

\footnotetext{
${ }^{1}$ Thompson 1979 and O’Brien 1991 are early exceptions from anthropology and sociology, respectively.
} 
structured operation across more than 6,000 miles of streets, six and seven days a week, twelve months a year. ${ }^{2}$ It marshals an annual budget of $\$ 1.6$ billion and moves roughly 13,000 tons of discards every day while simultaneously attending to constant and unpredictable demands from the larger city. ${ }^{3}$ Depending on whether the job is done well or badly, Sanitation safeguards or endangers public health, enhances or compromises basic quality of life, and makes or destroys the careers of various powerbrokers. ${ }^{4}$ Despite this, the Department and its employees are generally scorned, even though its mission is fundamental to the wellbeing of the metropolis it serves and even though the job of sanitation worker is one of the most hazardous occupations in the nation (BLS 2014). The agency is rigidly hierarchical, has a stark division between uniformed and civilian job titles (there are roughly 7,000 of the former, 2,000 of the latter), and thoroughly distrusts outsiders-especially outsiders who want to write in detail about this particular "tribe."

I first approached the DSNY with a research proposal in the late 1990s. I told Department officials that I wanted to learn its dynamics and daily rhythms from the perspective of those who drive municipal garbage trucks and pick up New York's household refuse-that is, by working with the city's ground troops in its perpetual war on grime. My goal was to show the elemental realities of labor that I believe is the most important in any urban arena.

There are two main reasons for its primary significance. If urban solid waste management isn't effective, public health is soon compromised to the point where people start suffering diseases that have been held in check for decades. Reformer and journalist Jacob Riis observed in 1902 that clean streets and regular garbage collection had "saved more lives in the crowded tenements than a squad of doctors." Today the job is done well enough to let the public forget that Riis's claim is just as true now as it was a century ago.

Economic well-being is equally dependent on competent garbage handling systems: if we can't discard what we no longer want, we risk

\footnotetext{
${ }^{2}$ Street-mile calculations depend on many variables. Mechanical brooms (street sweeping vehicles) clean a street along one curb at a time, but streets have a curb on two or more sides. When planning a broom route, a single street-mile must be calculated as at least two curb-miles. Snow plows cover approximately one lane at a time; for plowing, one mile of a four-lane avenue is measured as four lanemiles.

3 The budget figure, for fiscal year 2016, comes from the Council of the City of New York (2015). The household waste collected by the DSNY is roughly a third of New York City's daily total. The other two thirds are made up of commercial waste and a category called C\&D, for construction and demolition debris.

${ }^{4}$ I write Sanitation (upper-case S) and not sanitation (lower-case s) because I'm referring specifically to the Department of Sanitation by name, not to a homogenized or generic idea of sanitation as infrastructure or civic concern.
} 
being overwhelmed by our stuff. ${ }^{5}$ And in a more basic measure, garbage that is not wrestled into stasis-trash for which there is no management-signals general decay, lack of order, impending chaos. It carries big, bad symbolic weight.

The Department, I explained to Sanitation bosses, stands between New Yorkers and those collective horrors. If the public more fully understood the job and were better acquainted with the people who do it, I argued, some of the persistently negative attitudes toward the DSNY might shift. In short, I was trying to convince Department brass that my research of Sanitation would result in benefits for them.

My investigation fit into larger concerns about climate change and the likelihood that Homo sapiens will or will not survive the Anthropocene. ${ }^{6}$ If we are to change the way we inhabit a world marked by an increasingly tempestuous environment and by ever-widening disparities between the planet's wealthiest and poorest citizens, we in richer nations must understand all the consequences of the way we live. This includes scrutiny of large-scale industrial, economic, and political processes, and it must also focus on the multiple costs borne by individual human beings. These have been tallied in many ways in many sources, ${ }^{7}$ but it seemed to me that one important perspective was glaringly absent. Though efficient solid waste management is an absolute necessity for any healthy municipality, there was scant research on the workers and

\footnotetext{
${ }^{5}$ Someone who has particular trouble discarding or otherwise letting go of things (broadly defined) and instead holds onto them obsessively and excessively is called a hoarder. Hoarding behavior can be stressful, disruptive, and even physically harmful. See Lidz 2003 for a nonfiction account and Doctorow 2009 for a novel about the Collyer brothers, a famous and tragic example of extreme hoarding in New York City. From 2009 to 2013, a reality-television series called "Hoarders" profiled the plight of hoarders across the United States. See Frost and Steketee 2010 for a study of hoarding behavior as a component of mental disability. In 2013, "hoarding disorder" was added to the DSM-V (the most recent edition of the Diagnostic and Statistical Manual of Mental Disorders, a comprehensive compendium published by the American Psychiatric Association). The Oxford Handbook of Acquiring and Hoarding was published in 2014.

6 The label Anthropocene refers to the profound impact of human activity on the global environment and asserts that such activity is now a permanent part of Earth's geological record. Stratigraphers, geologists, and environmentalists, among others, are still debating whether or not it should be the official designation for the contemporary era. For an overview, see Monastersky 2015. For a concise argument in favor of the term, see Stager 2011: 4-12. See Hann 2016 for a discussion of anthropological engagement with the idea.

${ }^{7}$ To name only a few examples, see Bales 2004 on international human rights violations and economic injustice; Kolbert 2014 on the growing possibility that environmental devastation will result in human extinction; McKibben 2013 on the importance, and personal toll, of environmental activism; Rivoli 2006 on the global exploitations of labor and ecology that stand behind a commodity as humble as a t-shirt; Rogers 2010 on the tie between capitalism, greenwashing, and anti-environmental politics.
} 
managers who create and maintain such systems (exceptions include Corteel and Le Lay 2011, Perry 1998 and Reno 2009, 2016). ${ }^{8}$ I wanted to address that gap by learning from the people charged with keeping North America's largest city clean-or, as one source phrased it, keeping it alive (Ukeles 2002).

Because my goals were straightforward and because I wanted to tell a positive story, I assumed my proposal would be accepted with enthusiasm. Research, as I imagined it, would take several months in locations across the city, and of course I'd be welcomed wherever I went. It didn't occur to me that there would be no interest in my idea and no need for my project. I didn't realize that I was the umpteenth person with an of/for Sanitation proposal; my anthropology bona fides did nothing to help me stand out from a crowd of similarly enthusiastic, similarly clueless journalists, students, and documentary film makers.

In hindsight, I wonder at my naïveté. I was not new to ethnographic research, ${ }^{9}$ but my attitude toward Sanitation was that of an inexperienced first-timer. It was a classic dilemma of fieldwork access: without an insider advocate to champion my cause, or even just a Sanitation acquaintance who could vouch for me, no one within the DSNY had any reason to welcome me. ${ }^{10}$ When the Department still did not embrace me or my project after many months of communication, I was confused and discouraged. I didn't yet understand the culture of bureaucracy.

\section{Models and flaws}

Max Weber charted the territory a century ago. He wasn't the first (Karl Marx and John Stuart Mill were among those who preceded him), and of course much has been done since, but his insights still hold. ${ }^{11}$ In its truest form, Weber argued, a bureaucracy is organized around a "fixed and official jurisdictional area" with responsibilities distributed across a transparent hierarchy that abides by uniformly applied rules. It keeps meticulous records; jobs and promotions are given according to clearly

\footnotetext{
${ }^{8}$ Solid waste refers to various forms of garbage or trash and is distinct from human waste, which is called sewage. Reid 1991 is an able history of Parisian sewer workers; more recently, sewer workers in Montpellier where the subject of an ethnography by Jeanjean 2006.

${ }^{9}$ Nagle 1997.

10 On the importance of an insider advocate, and its potential pitfalls when trying to gain access to a field site, see Fetterman 1998: 33-34. Fine 2013 discusses the problem of trust in the context of a hierarchical work place; his experiences in a restaurant kitchen were very similar to mine once I was finally allowed to start fieldwork.

11 There is a rich literature of bureaucracy studies, but a review is beyond the scope of this paper.
} 
delineated metrics of appropriate skill (rather than according to who knows or owes whom, or according to sacerdotal or royal decree). Management requires training in specialized functions, and officials charged with running the bureaucracy owe it their "full working capacity" - that is, theirs is not a part-time job or mere honorific title (Weber 1958 [1946]: 196-198).

New York City's Department of Sanitation fits this model perfectly-except when it doesn't. The Department's jurisdictional area seems clear: it is in charge of garbage collection, street cleaning, and snow removal. Those responsibilities are a subset of the city's obligation to safeguard public health by protecting its residents from the many hazards that trash would unleash if left untended. But the problem of garbage in New York is delegated according to its source and context. The public at large doesn't generally understand that garbage, as a category of material and as a management challenge, is handled by different entities depending on its genesis and where it accumulates. The DSNY is concerned with household waste, which accounts for only a third of the city's total. The other two-thirds are made up of commercial waste (generated by restaurants, stores, businesses, etc.) and what's known as C\&D, or construction and demolition debris. More than 200 private carting companies pick up the city's C\&D and commercial waste. And while a single public agency manages municipal household waste, it's not responsible for all public trash. When left behind in New York City's parks, garbage is the burden of the Department of Parks and Recreation. In the subway system, it's cleaned up by the Metropolitan Transit Authority. Highway litter belongs to the Department of Transportation.

But the very matter at the heart of Sanitation's purpose-refusepresents deeper problems. Garbage does not respect jurisdictional boundaries, nor does it submit to mechanisms of bureaucratic control. It is in such perpetual motion that waste managers use the language of water: waste streams flow from specific waste sheds. Like water, waste spreads to fill the space allowed it, and it regularly breaches its containments. Sometimes Sanitation's basic mission feels like plugging holes in a dyke that has so many leaks it's about to burst. The Department has no power to stem the deluge-the source originates far upstream from any single municipal system-but the public often demands that the DSNY do more to reduce the amount of trash that New Yorkers create. That's rather like asking the neighborhood mortician to lower his community's mortality rate. Imagine if any public agency were charged with legislating and monitoring the minute details of our daily consumption habits and concomitant disposal behaviors. It would be the ultimate imposition of government bureaucracy on private life. Indeed, when curbside recycling was reintroduced to New York in 1989 (the first effort was in the 1890s), the press reported city-wide grumbling along the lines of "How dare the government tell me what to do with my trash!" 
Weber could not have anticipated the troublesome nature of the material that forms Sanitation's jurisdictional area, nor could he have predicted the public's hostility toward that material and toward the Department itself.

Another of Weber's requirements concerns record-keeping. Sanitation's is meticulous, but it's also situational and short-lived. Details about who worked where, for how long, with what result, in which piece of equipment (itself given a paper trail that tracks consumption of petrol, motor oil, hoist fluid) are noted with extreme care, as are facts about the weight and dumping location of each truckload of garbage. But the ledgers that hold these data are saved only a few years. State and city laws about record-keeping schedules aren't flouted so much as they aren't taught; in part because the DSNY is very good at getting rid of things, and because there is no training within the agency about what to do with documents over time, files and paperwork that could or should be preserved are often lost. This is not a trivial problem. The history contained within archival material tells intimate details that cannot be conveyed by any other means. Grand architectural monuments are meant to stand against time, but the stories that inspired their creation are often forgotten. Archives, in contrast, can help us understand a narrative arc of history that anchors us to the past and that one day will reveal us to our descendants. When a wealth of Department information comes into being and then disappears, along with it goes the chance for a more thorough, nuanced, and informative history of the agency, of the city it serves, and of larger forces at play across a range of economic, political, and infrastructural arrangements.

Here's one more way in which the Department both follows and departs from the Weberian model. Promotion opportunities are determined with carefully crafted measures of competence, just as Weber says they should be, but those measures are contentious. Ethnic and gender disparities in various job titles are corrected by lawsuits, by court orders, and by decisions at the upper echelons of Department leadership. When people are promoted, their new titles require them to master new forms of expertise and competence, but training and support are sometimes insufficient. The transition from sanitation worker to supervisor is especially stressful. It's the first step up the ladder for uniformed employees, and is the moment when workers are yanked into the managerial class. If a person can't make it as a supervisor, all future promotional opportunities in the uniformed ranks are closed.

Labor issues in general provide challenges. Because the Department stands as management in relation to unionized sanitation workers, officers, chiefs, and civilian personnel, it must always balance its policies with the varied and sometimes contradictory demands of its wellorganized labor force. The work has been structured as an on-going military campaign since 1895 , but unlike a conventional army, most ranks 
have shop stewards and business agents representing their interests. The influence of the sanitation workers' union in particular, 6,000 or so members of Teamsters Local 831, far exceeds its modest size.

In short, Weber's ideal can't account for changes in political whim, histories of policy accumulation, or forces external to the Department's immediate mission but regularly complicating its day-to-day routine. More importantly, from my perspective, Weber neglects the influence of human volition. Organizational success depends on managers having a combination of "incentives, culture, and authority" (Wilson 1991: 365). These three essentials are not always available in Sanitation, but their absence can be overcome. Within any institutional setting are individuals whose choices can invigorate or discourage colleagues, inspire or demean subordinates, support or undermine superiors, facilitate or obstruct work. Specific people refused to answer when I first knocked on Sanitation's door, and then some of those same people, reacting to slightly altered circumstances, let me in. Observing their access to and exercise of a casual but all-controlling power was enlightening.

\section{An awkward fit}

Any corporate or municipal or academic organization of any appreciable age and size follows a cardinal rule of communication: when an unusual request crosses their desks, bureaucrats will, with few exceptions, just say no. If the idea is outside the parameters of business-as-usual, resembles no other model of successful work, comes from an unknown source who lacks internal advocates, and guarantees no positive outcome (that is, has no relevant deliverables), there is no motive for anyone within the organization to approve it. On the contrary: because both the petitioner and her proposal represent several different but simultaneous forms of risk, there is clear motive to turn her down-or, even more cautiously, to deny her a firm yay or nay.

A change of leadership can significantly alter an organization's internal culture. My request to do research with the DSNY languished in administrative purgatory for a long time. After a mayoral election, however, the old guard left, and among the new players were people who knew people I knew-in other words, I suddenly had insider advocates. More than two years after I'd first reached out to the Department, I was granted my first face-to-face meeting with a Sanitation official who had the authority to approve my plan. By then I was wise to the ways of municipal decision-making: the official didn't give me a green light, but because he didn't turn me down, I considered the conversation a success.

Old bureaucracies can embrace new ideas, but it helps if institutional uncertainties are alleviated, if the potential utility of the innovation is made clear, and if the newcomer (who happens to be the one with the new idea) can prove herself trustworthy. 
I spent the summer and early fall of 2002 in the Sanitation official's office reading through a collection of archival material. By October I'd shown enough credibility to be allowed a single half-hour visit to a Sanitation garage at the end of a day shift, where I was permitted to interview one worker while under the watchful eye of the garage superintendent. It was the first of what became a regular series of visits, which grew into less formal, more social connections with Sanitation workers, officers, and civilian employees, which opened the possibility for access to other corners of the Department.

In a really big organization, a researcher can only go so far as a participant observer. After two years of fieldwork, I had established a good rapport with DSNY personnel around the city, but by then I realized that I needed to go deeper. I took the required civil service exams, cleared various medical hurdles, learned to drive a garbage truck, passed the road test for my commercial driver's license, and was hired as a uniformed New York City sanitation worker. Some friends inside the Department were delighted by my choice and encouraged me throughout the many steps of the hiring process, but not everyone was pleased. As one chief said to me, "We take this job so our children don't have to take jobs like this." No matter how many times I tried to explain my motives, it made no sense to him that a college professor wanted to be a sanitation worker. He couldn't see that there was no other way for me to learn what I needed to know.

And it was quite the education. For the few months I was in title, I drove collection trucks, operated mechanical brooms, and plowed snow; through that process, I crossed the line from both of and for, and established a genuine with. The experience gave me insights that I never would have had otherwise, and it distinguished me from the many other would-be chroniclers of Sanitation life. They came and went. I came, stayed, and joined the force.

Bureaucracies must assign everyone within them a place and a definition. When I took the job of sanitation worker and then resigned, I generated a fresh round of confusion. If I were just a researcher, why did I take the job in the first place? If I were really a sanitation worker, why did I leave it after only a short time? Where did I fit within the DSNY, anyway, and what was my project really about? The bureaucratic categories of city government had no pre-existing slot for a roaming scholar. Lack of clarity about the anthropologist's context and classification is anathema to healthy ethnographic research, especially in an organization as complex and tightly knit as Sanitation. I needed a fixed position within its institutional framework. I also needed a title that I wouldn't have to quit, that would let me be an anthropologist, and that would serve the Department. The model for a solution was close at hand. 


\section{In residence}

When the artist Mierle Laderman Ukeles first became a mother, she chafed at the messy, isolated tedium of childrearing. It was, she realized, basic maintenance work: repetitive, mundane, invisible, and essential to the well-being of what was maintained-in this case, her family. But what if that labor were understood differently? Did it have to be separate from her identity as an artist? Why not designate maintenance work as a form of art? She introduced her idea in her now-famous "Maintenance Manifesto," a fiery, articulate demand that the world recognize the false separation between, on the one hand, process, development, and creativity, and, on the other hand, tending, caring, nurturing, shepherding: the basic tasks of maintaining. ${ }^{12}$ There can be no revolution-or even survival-without both.

Her first project in the new genre was with maintenance workers at a branch of the Whitney Museum in downtown Manhattan. A glowing review in the Village Voice suggested that perhaps this innovative art form meant the Department of Sanitation could qualify for funding from the National Endowment for the Arts (Bourdon 1976). According to Ukeles, a few days later she received a phone call from Sanitation's commissioner, who asked her, "How'd you like to make art with 10,000 workers?" "I'll be right down," Ukeles replied. Her first piece with the DSNY was a performance work called "Touch Sanitation." For eighteen months between 1979 and 1980, she visited every Department facility in the city, shook hands with every sanitation worker on the force, and said to each one, "Thank you for keeping New York City alive." Shortly thereafter she was named the Department's artist-in-residence, an unsalaried position she has held ever since. ${ }^{13}$

By the time I found myself without location or definition within the DSNY, I had known Ukeles for several years. I asked if she thought the Department had room for both an artist and an anthropologist. When she embraced the idea, I suggested it to Sanitation's leadership. After Department lawyers scrutinized my proposal to make sure the arrangement would not impose any obligations upon nor create risks for Sanitation or for the city, I was named the DSNY's anthropologist-inresidence (like the artist, also unsalaried). The title gave me a place within Sanitation's institutional scaffolding-it was understood that I would be part of the Office of Public Affairs-and gave me a classification,

\footnotetext{
12 For the full text of "Maintenance Manifesto," see http://sites.moca.org/wack/2007/07/25/mierle-ukeles-manifesto-formaintenance-art-1969/

13 Ukeles' example has inspired at least one other waste management organization to host artists. Recology, the company responsible for collecting San Francisco's municipal and commercial waste, has had an artist-in-residence program since 1990. http://www.sfrecycling.com/index.php/about-air
} 
even if few people inside the organization knew anything about anthropology. The title also gave the Department bragging rights; as the Commissioner for Public Affairs pointed out to various media sources, Sanitation is the only government agency in New York with its own inhouse social scientist (see, for example, McGrath 2006 and Haberman 2008).

In common usage, to reside somewhere means to occupy, live within, or inhabit a place. To be "in residence" can have the same connotation, but it's also used to mean "formally affiliated with." Residency programs are often found in arts organizations (Res Artis in the Netherlands has an international list) and in academic settings (there are hundreds of examples around the world). They can take many forms, but broadly speaking, an individual "in residence" is hosted by an organization that provides time and space for her to pursue a creative endeavor; in exchange, she may offer lectures, workshops, classes, or an exhibition, or simply acknowledge the organization's support when work results from the residency. Whatever its particulars, the arrangement is meant to serve both parties.

Concern about of versus for had been put aside long before I invented my new title, but an anthropologically informed and institutionally formalized relationship between myself and Sanitation makes the with explicit and clarifies the mutual benefit of our association. It lets me create a permanent affiliation with my research site and stay involved in the life of the Department for the long term. It also amplifies my voice. Part of my responsibility to Sanitation is to communicate on its behalf whenever and however possible. Journal articles and scholarly publications can reach my fellow academics, but that by itself is too narrow. My association with the DSNY arouses curiosity in places far from the academy. I give public lectures in many venues, speak regularly to various media, and in 2013 did a TED talk. This has a triple impact. I am representing sanitation work in general and New York in particular; I am also putting anthropology into the world through an unusual context, and that lets me proselytize, directly and indirectly, for the discipline.

For its part, the DSNY is pleased that my work consistently addresses themes fundamental to its overall message, and newcomers to the Department find my insights helpful in understanding the culture of the world they've just joined. There have even been signs that my basic message about Sanitation's importance in the life of the city is beginning to spread (Bobrow 2016; Hennessy 2014; Mann 2014; Newman 2014).

\section{Partnership}

After more than a decade of anthropological trial and error with 
Sanitation, I see possibilities for fruitful new partnerships between academics and various bureaucratic organizations. As anthropologists, we build our careers around research that we hope creates insightful understandings of the mess and beauty of human culture as a foundational "actant" (pace Latour) across the globe. What if some of that effort supported the just and sustainable efficacy of public authorities?

Bureaucracies in any context are often concentrated nodes of mundane power. It can seem at times as if bureaucrats exist simply to invent pointless new forms of control (du Gay 2000). When a disgruntled public clamors for less government, the demand is partly a protest against intrusive, confusing impositions of bureaucracy made manifest in many forms (using all meanings of that word). Errors on the part of government functionaries can seem like intentional gestures of disrespect, but more often than not they are "simple but ineluctable failures to communicate" (Kafka 2012:12). That's where anthropologists come in. If our work is clearly relevant to causes bigger than our disciplinary affiliations and academic careers, many bureaucratic institutions might be eager for us to help them articulate and achieve goals, measure impact, even help build a brighter organizational future. Anthropology could have a vital and creative role in a variety of settings where it currently has no presence. The key to such an arrangement is to be aware of its potential limitations while making good use of its privileges.

A primary constraint comes from the relationship itself. My bond with Sanitation is like a form of kinship: loyalty prevents me from writing about some elements of the job, though no one in the Department ever articulated such a rule. Because I am their in-house social scientist, whenever I speak or write about Sanitation, I'm also speaking and writing on the agency's behalf. I don't dissemble when telling Sanitation stories, but I don't necessarily share my opinion when asked about politically sensitive DSNY concerns. In other words, my scholarly work is not entirely my own. If a more orthodox anthropologist would argue that therefore my research is incomplete, I'd counter that all social science is incomplete, especially if we are guided by the precept to do no harm.

Then there's the way in which a long-term connection to a single institutional field site can alter the researcher's perspective. I no longer speak only as an anthropologist. That's no hardship: like many of my colleagues, I aim to be an anthropologist in service of the larger world. Without a specific focus, however, that goal is too vague to be meaningful, so I concentrate my efforts on the slice of the world that is the DSNY. This perspective allows me a meta-level view of the entire organization and the city it serves, while at the same time it helps me understand finegrained details of particular events, places, and controversies. The duality is enhanced by deep knowledge of the institution's history and by noting how changes in any part of the organization affect the dynamic of work in other areas. The dual perspective also implies a dual obligation. One of my 
tasks is to translate Sanitation to the larger world, and another is to translate Sanitation back to itself.

The people of the DSNY continually teach me new insights, perspectives, and logistical details about themselves, their work, and the city they serve, and I share those lessons with many audiences. ${ }^{14}$ Readers and listeners are often astonished to realize how little they know about, and how completely they take for granted, an infrastructure on which their lives depend. They are equally startled to see that the effectiveness of the system requires the skill of an eclectic sub-culture of talented men and women whom they had never before considered. In some cases, it's a revelation that inspires a new attitude toward the Department, and helps members of the public understand that there are many ways to collaborate in the success of Sanitation's mission. ${ }^{15}$

Another element of this is to be vigilant for, and offer corrections of, media reports about the DSNY that are misleading or just plain wrong. These are especially common when the Department is accused of failing to fulfill some part of its mandate. ${ }^{16}$ The speed of journalistic output in the age of the internet has allowed more news through more venues than was possible even half a decade ago, but as a result, misinformation is created faster and travels farther than ever before. Sanitation is not given much affection even when there is no negative press, but when a derogatory story gets widespread attention, the public responds with venom - and they don't just write angry letters to the editor or spew bilious comments on a web page. Sanitation workers across the city have been verbally insulted, spat upon, threatened with guns, had their cars vandalized. Bad press, and especially sloppy bad press, can have violent consequences. ${ }^{17}$

The other side of my dual perspective is to translate the Department back to itself. I am one of the few people in the DSNY with access to and knowledge of the entire structure of the job. Though I will always be a beginner in an organization as historically rich and

${ }^{14}$ I chose to publish my book Picking Up with a trade press. It speaks to my fellow anthropologists, but it was intended to reach beyond the confines of the academy. As of mid-2015, my TED talk has had more than 1.5 million views. See http://bit.ly/1rgOGti.

15 This speaks to a growing trend of encouraging more fully collaborative relationships between public administration and the public at large (Trudeau 2011).

16 It's a problem not unique to Sanitation; large government agencies "are imperfect, vastly complex, usually reliable, and noticeable only when they break down" (Goodsell 1994 [1983]: 4).

17 The DSNY was the target of public fury incited by grossly inaccurate press coverage of the Christmas Blizzard of 2010; Goldenberg 2010 is one typical example. For more complete details about that storm and its aftermath, see Nagle 2014: 200-209. 
strategically complex as Sanitation, I often know more than people who have been on the job for decades but have only worked in a few locations or at a single rank. Department personnel in general do not always understand the full implications or large-scale consequences of their work. When I give talks at DSNY benevolent society meetings or in training classes for new hires, I try to illuminate less obvious elements of Sanitation's role in the city and to explain the sometimes mysterious connections between different agency bureaux. More recently I've been suggesting that some bureaux within the agency should consider including uniformed workers when planning structural changes to the job. Managers in charge of such projects have a habit of concentrating almost exclusively within their own enclaves of expertise. When their efforts are not unanimously applauded, this group takes it as proof that "the uniforms" (as sanitation workers and officers are called) are an ungrateful lot.

Whatever their title, wherever they are located within the DSNY, however much they grumble about each other, all Department personnel are constantly striving to balance the requirements of their pre-defined, historically situated, sometimes institutionally calcified jobs with their own unique creativities. They insist on themselves, despite and sometimes against the weight of the bureaucratic power that would dictate the minutiae of their professional lives. My job as their anthropologist is to continue blending the of and the for into a mutual with, as well as to keep reminding them that they're doing the most important work in the city. Not everyone agrees with my claim, but it always inspires a lively debate.

\section{References}

Bales, K. 2004 Disposable People: New Slavery in the Global Economy. Berkeley: University of California Press.

Bobrow, E. 2016 'The Sanitation Department's Resident Anthropologist Wants to Clean Up the Image of Garbagemen.' Crain's New York Business, June 15.

Bourdon, D. 1976 'An Apocalyptic Paperhanger Shows His Stripes.' Village Voice, October 4; p105.

Bowker, G. and S.L. Star 2000 Sorting Things Out: Classification and Its Consequences. Cambridge, MA: MIT Press.

Cantwell, A-M. and D. d. Wall 2003 Unearthing Gotham: The Archaeology of New York City. New York: Yale University Press.

Corteel, D. and S. Le Lay 2011 Les travailleurs des déchets. Paris: Érés. Council of the City of New York. 2015 'Report on the Fiscal 2016 
Preliminary Budget and the Fiscal 2015 Preliminary Mayor's

Management Report.' March 25.

Doctorow, E.L. 2009 Homer \& Langley: A Novel. New York: Random House.

du Gay, P. 2000 In Praise of Bureaucracy: Weber, Organization, Ethics.

London: SAGE.

Fetterman, D.M. 1998 Ethnography Step by Step, 2nd ed. Thousand Oaks, CA: Sage.

Fine, G.A. 2013 If You Can't Stand the Heat: The Business of Observing Restaurant Kitchens. In Briody, E.K., et al, Opinions: Ethnographic Methods in the Study of Business. Journal of Business Anthropology 2(2):141-144.

Frost, R. O. and G. Steketee, eds. 2014 The Oxford Handbook of Acquiring and Hoarding. New York: Oxford University Press.

Frost, R. O. and G. Steketee 2010 Stuff: Compulsive Hoarding and the Meaning of Things. New York: Houghton Mifflin Harcourt.

Goldenberg, S. 2010 'Sanitation Department's Slow Snow Cleanup was a Budget Protest.' New York Post, December 30.

Goodsell, C. T. 1994 [1983] The Case for Bureaucracy: A Public

Administration Polemic, 3rd ed. Chatham, NJ: Chatham House Publishers.

Haberman, C. 2008 'Collecting the Trash: Its Science and Value.' The New York Times, January 15.

Hann, C. 2016 'The Anthropocene and Anthropology: Micro and Macro Perspectives.' European Journal of Social Theory, May 23:

1368431016649362.

Hennessey, M. 2014 'The Toughest Job in Town.' City, June 27.

Jeanjean, A. 2006 Basses oeuvres : une ethnologie du travail dans les egouts. Paris: Cths Edition.

Kafka, B. 2012 The Demon of Writing: Powers and Failures of Paperwork. New York: Zone Books.

Kolbert, E. 2014 The Sixth Extinction: An Unnatural History. New York: Henry Holt and Co.

Lidz, F. 2003 Ghosty Men: The Strange but True Story of the Collyer Brothers. New York: Bloomsbury.

Mann, B. 2014 'America's never-ending war against garbage.' North Country Public Radio, April 9.

Martin, L. and N. Russell 2000 “Trashing Rubbish.” In I. Hodder, ed., Toward a Reflexive Method in Archaeology. Cambridge, UK: McDonald Institute Monographs.

McGrath, B. 2006 'Dr. Garbage.' The New Yorker, November 13. 
McKibben, B. 2013 Oil and Honey: The Education of an Unlikely Activist. New York: Times Books.

Monastersky, R. 2015 Anthropocene: The Human Age. Nature 519(7542): 144-147.

Nagle, R. 1997 Claiming the Virgin: The Broken Promise of Liberation Theology in Brazil. New York: Routledge.

Nagle, R. 2014 Picking Up: On the Streets and Behind the Trucks with the Sanitation Workers of New York City. New York: Farrar, Straus and Giroux. Newman, A. 2014 'Why the Garbage Man Might Not Like Your Dog.' New York Times, p. A24.

O'Brien, M. 1991 Rubbish-Power: Toward a Sociology of the Rubbish Society. Consuming Cultures: Power and Resistance. J. Hearn and S. Roseneil, eds. New York: St. Martin's Press.

Perry, S. 1998 Collecting Garbage: Dirty Work, Clean Jobs, Proud People. Piscataway Township, NJ: Transaction Publishers.

Rathje, W. 1984 The Garbàge Decade. American Behavioral Scientist 28(1): 9-29.

Rathje, W. and C. Murphy 1992 Rubbish! The Archaeology of Garbage. Tucson: University of Arizona Press.

Reid, D. 1991 Paris Sewers and Sewer Workers: Realities and Representations. Cambridge, MA: Harvard University Press.

Reno, J. 2009 'Your Trash is Someone's Treasure: The Politics of Value at a Michigan Landfill.' Journal of Material Culture 14(1): 29-46.

Reno, J. 2008 'Out of Place: Possibility and Pollution at a Transnational Landfill.' Ph.D. dissertation, University of Michigan.

Riis, J. 1969 [1902] The Battle with the Slums. Montclair, NJ: Patterson Smith.

Rivoli, P. 2006 The Travels of a T-Shirt in the Global Economy: An Economist Examines the Markets, Power, and Politics of Free Trade. New York: Wiley.

Rogers, H. 2010 Green Gone Wrong: How Our Economy is Undermining the Environmental Revolution. New York: Scribner.

Stager, C. 2011 Deep Future: The Next 100,000 Years of Life on Earth. New York: St. Martin's Press.

Thompson, M. 1979 Rubbish Theory: The Creation and Destruction of Value. New York: Oxford University Press.

Trudeau, L. 2011 The Evolution of Collaboration. Transforming American Governance: Rebooting the Public Square. A.P. Balutis, T.F. Buss, and D. Ink, eds. Armonk, NY: M.E. Sharpe. 
Ukeles, M. L. 2002 'Leftovers / It's About Time for Fresh Kills.' Cabinet 6; Spring. http://www.cabinetmagazine.org/issues/6/freshkills.php

U.S. Department of Labor, Bureau of Labor Statistics (BLS) 2014 "National Census of Fatal Occupational Injuries in 2013 (Preliminary Results)." September 11.

Weber, M. 1958 [1946] 'Bureaucracy.' From Max Weber: Essays in Sociology. H.H. Gerth and C. Wright Mills, trans./eds. New York: Oxford University Press.

Wilson, J. 1991 Bureaucracy: What Government Agencies Do and Why They Do It. New York: Basic Books.

Robin Nagle is the author of Picking Up: On the Streets and Behind the Trucks with the Sanitation Workers of New York City (Farrar, Straus and Giroux, 2014), an ethnography of the DSNY. She teaches anthropology and environmental studies at New York University and is anthropologist-inresidence for New York City's Department of Sanitation. 